\title{
Regulation of the hyaluronan system in ovine endometrium by ovarian steroids
}

\author{
Kabir A Raheem ${ }^{1,3}$, Waleed F Marei ${ }^{1,4}$, Karen Mifsud ${ }^{1,+}$, Muhammad Khalid ${ }^{2}$, D Claire Wathes ${ }^{1}$ \\ and Ali A Fouladi-Nashta ${ }^{1}$ \\ ${ }^{1}$ Reproduction Group, Department of Comparative Biomedical Sciences and ${ }^{2}$ Department of Veterinary Clinical \\ Sciences, The Royal Veterinary College, Hawkshead Lane, North Mymms, Hertfordshire AL97TA, UK, ${ }^{3}$ Department of \\ Veterinary Surgery and Theriogenology, Michael Okpara University of Agriculture, Umudike, Nigeria and \\ ${ }^{4}$ Department of Theriogenology, Faculty of Veterinary Medicine, Cairo University, Giza 12211, Egypt \\ Correspondence should be addressed to A A Fouladi-Nashta; Email: afouladi@rvc.ac.uk
}

${ }^{\dagger} \mathrm{K}$ Mifsud is now at School of Clinical Sciences, University of Bristol, Bristol BS1 3NY, UK

\begin{abstract}
In this study, we investigated steroid regulation of the hyaluronan (HA) system in ovine endometrium including HA synthases (HAS), hyaluronidases, and $\mathrm{HA}$ receptor-CD44 using 30 adult Welsh Mountain ewes. Eight ewes were kept intact and synchronized to estrous (day 0). Intact ewes were killed on day 9 (luteal phase; LUT; $n=5$ ) and day 16 (follicular phase; FOL; $n=3$ ). The remaining ewes $(n=22)$ were ovariectomized and then treated (i.m.) with vehicle $(n=6)$ or progesterone $(n=8)$ for 10 days, or estrogen and progesterone for 3 days followed by 7 days of progesterone alone $(n=8)$. Estradiol and progesterone concentrations in plasma correlated with the stage of estrous or steroid treatment. Our results showed trends $(P<0.1)$ and statistically significant effects $(P<0.05$, by $t$-test $)$ indicating that LUT had lower HAS1 and HAS2 and higher HAS3 and CD44 mRNA expression compared with FOL. This was reflected in immunostaining of the corresponding HAS proteins. Similarly, in ovariectomized ewes, progesterone decreased HAS1 and HAS2 and increased HAS3 and CD44, whereas estradiol tended to increase HAS2 and decrease CD44. Sometimes, HAS mRNA expression did not follow the same trend observed in the intact animals or the protein expression. HA and its associated genes and receptors were regulated by the steroids. In conclusion, these results show that the level of HA production and the molecular weight of HA in the endometrium are regulated by ovarian steroids through differential expression of different HAS both at the gene and at the protein levels.
\end{abstract}

Reproduction (2013) 145 491-504

\section{Introduction}

During the female reproductive cycle, the ovarian steroid hormones estradiol and progesterone play a central role in regulating reproductive events that lead to the establishment of pregnancy. In the endometrium, the estradiol-dominant follicular (FOL) phase of the estrous cycle is characterized by an increase in the blood flow, edema, growth of uterine glands, and mucus secretion (Aplin 2007). Subsequently, the progesterone-dominant luteal (LUT) phase of the estrous cycle is a window of receptivity of the endometrium to the conceptus and is characterized by uterine gland secretions, producing arrays of hormones, cytokines, and growth factors, collectively referred to as histotroph, which support the blastocyst before implantation (Roberts \& Bazer 1988). These changes in the endometrial environment require specific changes in the degree of tissue hydration and glycosaminoglycan content (Tellbach et al. 2002) and are associated with ovarian steroid-mediated changes in the composition and organization of glycosaminoglycans in the extracellular matrix (Cidadao et al. 1990).

Hyaluronan (hyaluronic acid; HA), the most abundant glycosaminoglycan, is naturally occurring in all animal tissues including the reproductive tract and its fluids. $\mathrm{HA}$ is composed of repeating disaccharide units of D-glucuronic acids and $\mathrm{D}-\mathrm{N}$-actetylglycosamine forming a linear polysaccharide (Weissmann et al. 1954). HA is synthesized by integral plasma membrane glycosyltransferases called HA synthases (HAS) of which there are three known mammalian isoforms: HAS1, HAS2, and HAS3, with different enzymatic properties and actions (Itano et al. 1999). While it is being synthesized, $\mathrm{HA}$ is extruded onto the extracellular surface (Tammi et al. 2002) resulting in production of $\mathrm{HA}$ molecules of various molecular weight reaching $>2 \times 10^{6} \mathrm{Da}$ (Toole 2004). HA is degraded by hyaluronidases (HYALs) for which six HYAL genes are identified in human with HYAL1 and HYAL2 being considered as the most important in degradation of $\mathrm{HA}$ in somatic cells 
(Lepperdinger et al. 2001). HYAL2 is localized extracellularly and depolymerizes HA into fragments of $\sim 25 \times 10^{3} \mathrm{Da}$, which may then be internalized and depolymerized by HYAL1 into oligosaccharides or tetrasaccharides (Stern et al. 2006).

In mammalian reproduction, $\mathrm{HA}$ is involved in oocyte maturation (Schoenfelder \& Einspanier 2003), fertilization, implantation (Babayan et al. 2008), and parturition (Straach et al. 2005). The HA level in the endometrium may also be used as an indicator to the physiological or pathological status of this organ (Nykopp et al. 2010). High-molecular-weight (HMW) HA produced by HAS2 is so crucial for mammalian embryogenesis that HAS2knockout embryos die in mid-gestation due to cardiac and vascular abnormalities (Camenisch et al. 2000). The biological functions of the HA molecules are known to vary depending on their size. HMW $\mathrm{HA}$ is antiangiogenic, immunosuppressive, and inhibits cell migration (Deed et al. 1997, Lee \& Spicer 2000). The functions of HMW HA are usually attributed to its unique hygroscopic and viscoelasticity physiochemical properties (Balazs \& Gibbs 1970). On the other hand, lowmolecular-weight (LMW) HA molecules initiate a molecular signaling pathway via their receptors such as CD44 (Aruffo et al. 1990, Aruffo 1996) or receptor for HA-mediated motility. HA-mediated cell surface signaling through CD44 is usually correlated with either cell migration or cell proliferation responses (Lee \& Spicer 2000) and hence may play an important role during embryo development and implantation. LMW HA is also known to be angiogenic and anti-apoptotic (Stern et al. 2006), which can be beneficial during placentation and embryogenesis. Collectively, and according to the previously formulated catabolic scheme of HA (Stern 2003), HA of a wide range of molecular weights may be present at all times in tissue, regulated by fine tuning of the expression of different HAS and HYALs, resulting in diverse biological effects.

While evidence for multiple roles of HA in mammalian reproduction continues to grow, its regulation by the ovarian steroids progesterone and estradiol has not been explicitly defined. Steroids have been reported to be involved in the regulation of HA synthesis in the uterine cervix in sheep (Perry et al. 2010a) and mice (Uchiyama et al. 2005). In this study, we examined changes in the components of the HA system in the endometrium of intact ewes at mid-LUT phase and FOL phase of the estrous cycle. In addition, to investigate the specific role of ovarian steroids in the regulation of $\mathrm{HA}$, we used ovariectomized ewes treated with progesterone (OVXP) or a combination of progesterone and estrogen (OVXEP) or vehicle $(\mathrm{OVX})$ and analyzed mRNA and protein expression of HAS (HAS1-3), HYALs (HYAL1 and HYAL2), and receptor CD44 and determined localization, content, and molecular weight distribution of the $\mathrm{HA}$ in the endometrium.

\section{Results}

\section{Plasma estradiol and progesterone concentrations}

Plasma progesterone concentrations were higher in LUT ewes $(2.3 \pm 0.49 \mathrm{ng} / \mathrm{ml})$ compared with FOL ewes (below detection limit of the assay; $<0.5 \mathrm{ng} / \mathrm{ml}$ ) on the day of killing and collection of endometrial samples. In ovariectomized animals, progesterone was not detectable in OVX control ewes, and it significantly increased in response to progesterone in the OVXP and OVXEP groups. The plasma estradiol concentration measured in the $\mathrm{FOL}$ group on the day of killing was $6.1 \pm 1.69 \mathrm{pg} / \mathrm{ml}$. In OVX and OVXPewes, plasma estradiol was below the detection limit, while in the OVXEP group that received estradiol injections for 3 consecutive days, estradiol levels started to increase following injections and continued to increase until day 10 of uterine sample collection.

\section{Effect of estrous cycle and ovarian steroids on mRNA expression of genes related to the $\mathrm{HA}$ system in the endometrium}

The data on endometrial mRNA expression of HAS (HAS1, HAS2, and HAS3), as well as HYAL1, HYAL2, and $C D 44$, during different stages of the estrous cycle in the intact ewes and in the ovariectomized animals treated with or without progesterone in the presence or absence of estrogen are presented in Tables 1 and 2 respectively. Expression of mRNA in endometrial samples from the LUT group tended to be lower for HAS1 $(P=0.09)$ and was significantly lower for HAS2 $(P<0.001)$ and significantly higher for HAS3 $(P=0.003)$ compared with the FOL group. Neither HYAL1 nor HYAL2 mRNA expression was affected by the stage of estrous cycle. CD44 was significantly higher in LUT compared with FOL tissue $(P=0.007)$.

In ovariectomized ewes, HAS2 and CD44 mRNA expressions were significantly reduced by administration of progesterone alone in the OVXP groups $(P<0.05)$ but not with combined treatment with both estradiol and progesterone in the OVXEP group $(P>0.05)$. HAS3 mRNA expression was significantly reduced in both OVXP and OVXEP compared with OVX tissue $(P<0.05)$. The levels of HYAL2 in the OVX group were almost

Table 1 Comparison of qPCR measurements for HAS1-3, HYAL1,2, and CD44 mRNA (expressed as copy numbers) in the endometrium of intact ewes at mid-luteal stage (LUT) compared to follicular stage (FOL) of the estrous cycle.

\begin{tabular}{llcc}
\hline Gene & \multicolumn{1}{c}{ FOL $(n=3)$} & LUT $(n=5)$ & P value \\
\hline HAS1 & $50040 \pm 15701$ & $25345 \pm 4040$ & 0.09 \\
HAS2 & $19143 \pm 346$ & $2139 \pm 433$ & $<0.001$ \\
HAS3 & $15070 \pm 3218$ & $29147 \pm 1404$ & 0.003 \\
HYAL1 & $66444 \pm 32189$ & $66808 \pm 15030$ & 0.99 \\
HYAL2 & $30095 \pm 1245$ & $30182 \pm 5498$ & 0.99 \\
CD44 & $12715 \pm 4480$ & $53939 \pm 7377$ & 0.007 \\
\hline
\end{tabular}

Data are presented as mean \pm S.E.M. and $t$-test was used for comparison. 
Table 2 Comparison of qPCR measurements for HAS1-3, HYAL1,2, and CD44 mRNA (expressed as copy numbers) in the endometrium of ovariectomized animals treated with only progesterone (OVXP) or estrogen and progesterone (OVXEP) compared with ovariectomized controls treated with vehicle $(\mathrm{OVX})$.

\begin{tabular}{|c|c|c|c|c|c|}
\hline Gene & OVX $(n=6)$ & OVXP $(n=8)$ & $P$ value & OVXEP $(n=8)$ & $P$ value \\
\hline HAS1 & $20190 \pm 5160$ & $44481 \pm 11580$ & 0.27 & $38503 \pm 8094$ & 0.58 \\
\hline HAS2 & $5538 \pm 1235$ & $3252 \pm 521$ & 0.04 & $3539 \pm 258$ & 0.07 \\
\hline HAS3 & $28526 \pm 1623$ & $18136 \pm 1920$ & 0.003 & $18081 \pm 1745$ & 0.003 \\
\hline HYAL 1 & $45253 \pm 3190$ & $69517 \pm 40930$ & 1.00 & $34321 \pm 2653$ & 1.00 \\
\hline HYAL2 & $59756 \pm 5000$ & $22395 \pm 2783$ & $<0.001$ & $25129 \pm 2164$ & $<0.001$ \\
\hline$C D 44$ & $12702 \pm 3846$ & $48395 \pm 11379$ & 0.03 & $17728 \pm 6941$ & 1.00 \\
\hline
\end{tabular}

Data are presented as mean \pm S.E.M. and one-way ANOVA was used for comparison.

double the expression in the FOL and LUT groups, and administration of progesterone with or without estradiol reduced HYAL2 mRNA expression $(P<0.001$ compared to $\mathrm{OVX}$ ) to levels approaching those observed in intact animals. HAS1 and HYAL1 did not differ among groups.

\section{Effect of estrous cycle and ovarian steroids on protein expression of $H A S$ and receptor CD44 in the endometrium}

Protein expression of the three HAS isoforms and HA receptor $\mathrm{CD} 44$ were examined by immunohistochemistry (IHC) and quantified using HSCORE. Generally, in the OVX group, the diameter of the uterine glands and the depth of luminal epithelium (LE) were observed to be smaller than in the OVXP and OVXEP groups. Immunostaining for all proteins examined was detected at variable intensities in the cytoplasm of all cell layers of the endometrium: LE, stroma (ST), and glandular epithelium (GE). HAS1 immunostaining was restricted to the nuclear region of the cells.

HAS1 immunostaining was significantly reduced in the LE and ST but not in the GE of LUT tissues compared with FOL tissues. Steroid-treated OVXP and OVXEP ewes also exhibited reduced HAS1 immunostaining mainly in the ST and GE regions compared with OVX controls $(P<0.05$; Fig. 1$)$.

HAS2 immunostaining was consistently higher in the FOL animals compared with the LUT animals in all endometrial layers $(P<0.05)$. Progesterone administration decreased HAS2 expression in LE and ST in OVXP compared with OVX. However, combined treatment with estradiol and progesterone in OVXEP had similar HAS2 expression compared to the OVX group $(P>0.1$; Fig. 2 ).

HAS3 immunostaining in LUT was significantly higher in the LE and GE $(P<0.01)$ and tends to be higher in ST $(P=0.079)$ compared with the $\mathrm{FOL}$ group. A similar pattern was observed in OVXP and OVXEP compared with OVX animals (Fig. 3).

CD44 expression in the LUT was distinct with a significantly $(P<0.05)$ higher HSCORE for all the three layers of the endometrium when compared with the FOL. CD44 expression in the LE and GE was increased by progesterone administration (OVXP) but not by combined estradiol and progesterone treatment (OVXEP) compared with the OVX group (Fig. 4).

\section{Effect of estrous cycle and ovarian steroids on $\mathrm{HA}$ immunostaining in the endometrium}

HA immunostaining using biotinylated HA-binding protein (b-HABP) revealed that $\mathrm{HA}$ is mainly localized within the ST compartment of the endometrium in all experimental groups, while very low or no staining was observed in the LE or GE (Fig. 5). The intensity and HSCORE of HA immunostaining in the ST in the FOL group (Fig. 5A) was significantly higher $(P=0.003)$ than in the LUT group (Fig. 5B). The latter expressed a moderate staining mainly restricted to the ST immediately beneath the luminal epithelia. In ovariectomized animals, HA immunostaining in the OVX group was high (Fig. 5D). This was significantly reduced by administration of progesterone alone $(P=0.001)$ or in combination with estradiol $(P=0.002)$ as observed in the OVXP or OVXEP groups respectively (Fig. 5E and F).

\section{Molecular weight of $\mathrm{HA}$}

The results of the HA electrophoresis and blotting with b-HABP are shown in Fig. 6A. Immunoreactive smears in Fig. 6A represent the distribution of $\mathrm{HA}$ in different treatment groups compared with four HA standards with known molecular weights loaded in the left lane. The highest and lowest molecular weight of $\mathrm{HA}$ in each treatment group were determined with AlphaEase software using the HA standards as molecular weight references with the results presented in a boxplot. The FOL group displayed increased levels of the highest-molecular-weight HA when compared with the LUT group $(P=0.009)$. The lowest molecular weight $\mathrm{HA}$ detected was significantly reduced in LUT ewes compared with the FOL group $(P=0.025$; Fig. $6 \mathrm{~B})$. In ovariectomized ewes, administration of progesterone only (OVXP) significantly reduced the highest molecular weight of HA detected compared with the OVX group. Combined treatment with estradiol and progesterone (OVXEP) abrogated this effect and the HA molecular weight was not significantly different from that for the OVX group (Fig. 6C). 

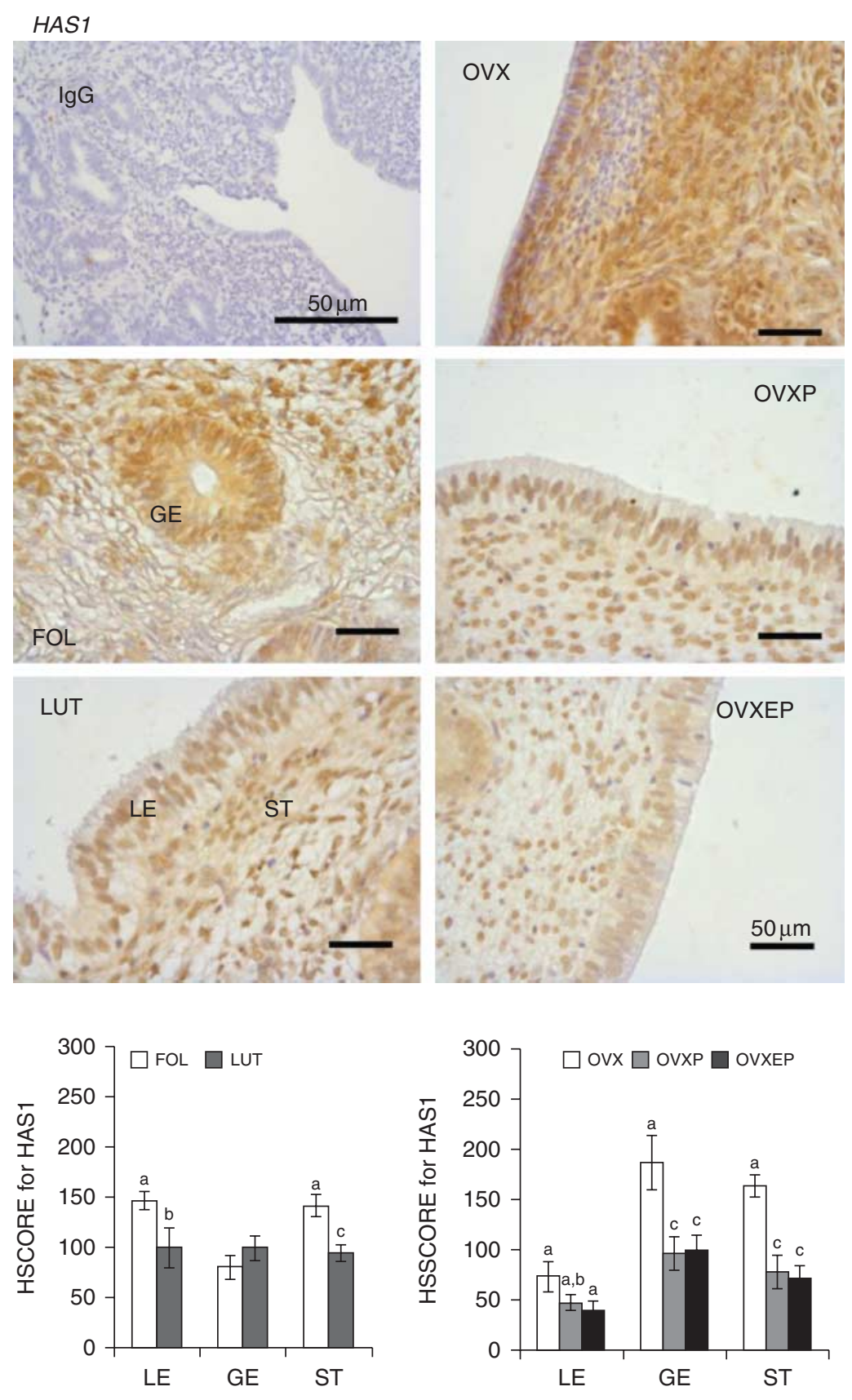

Figure 1 Immunohistochemical localization and quantification of HAS1 in the uterine endometrium in sheep at the follicular (FOL) and luteal (LUT) stages of the estrous cycle (left panels) and in ovariectomized ewes treated with vehicle (OVX), progesterone (OVXP), or estradiol and progesterone (OVXEP) (right panels). HAS1 is shown as brown staining (DAB) while nuclei are counterstained with hematoxylin. The HSCORE is shown as mean \pm S.E.M. Bars with different superscripts within the same layer are significantly different at a vs ${ }^{b} P<0.05$ or ${ }^{\text {a vs }}{ }^{\mathrm{c}} P<0.01$.

\section{Discussion}

In the OVXEP group, although estradiol was injected only during the first 3 days of treatment, the plasma estradiol concentrations remained high throughout the treatment period (10 days) until the animals were killed. This is likely to be due to a delay in absorption from the muscles at the site of injection. Thus, in contrast to the OVXP group treated only with progesterone, the endometrial samples from the OVXEP group were under the influence of both estrogen and progesterone until the day of sample collection, which possibly explains the difference in the expression pattern of some genes and proteins between OVXP and OVXEP groups, as discussed below.

The expression of the three HAS isoforms is organ- and cell-specific (Spicer \& McDonald 1998, Pienimaki et al. 2001, Straach et al. 2005). They are differentially regulated by various stimuli, suggesting distinct functional roles of the three proteins (Wang et al. 2009). Nevertheless, changes in the transcriptional levels of HAS mRNA do not always correlate with changes in the synthesis of HA (Recklies et al. 2001) due to posttranscriptional modification (Tammi et al. 2002). Therefore, in this study, it was necessary to examine HAS 
HAS2
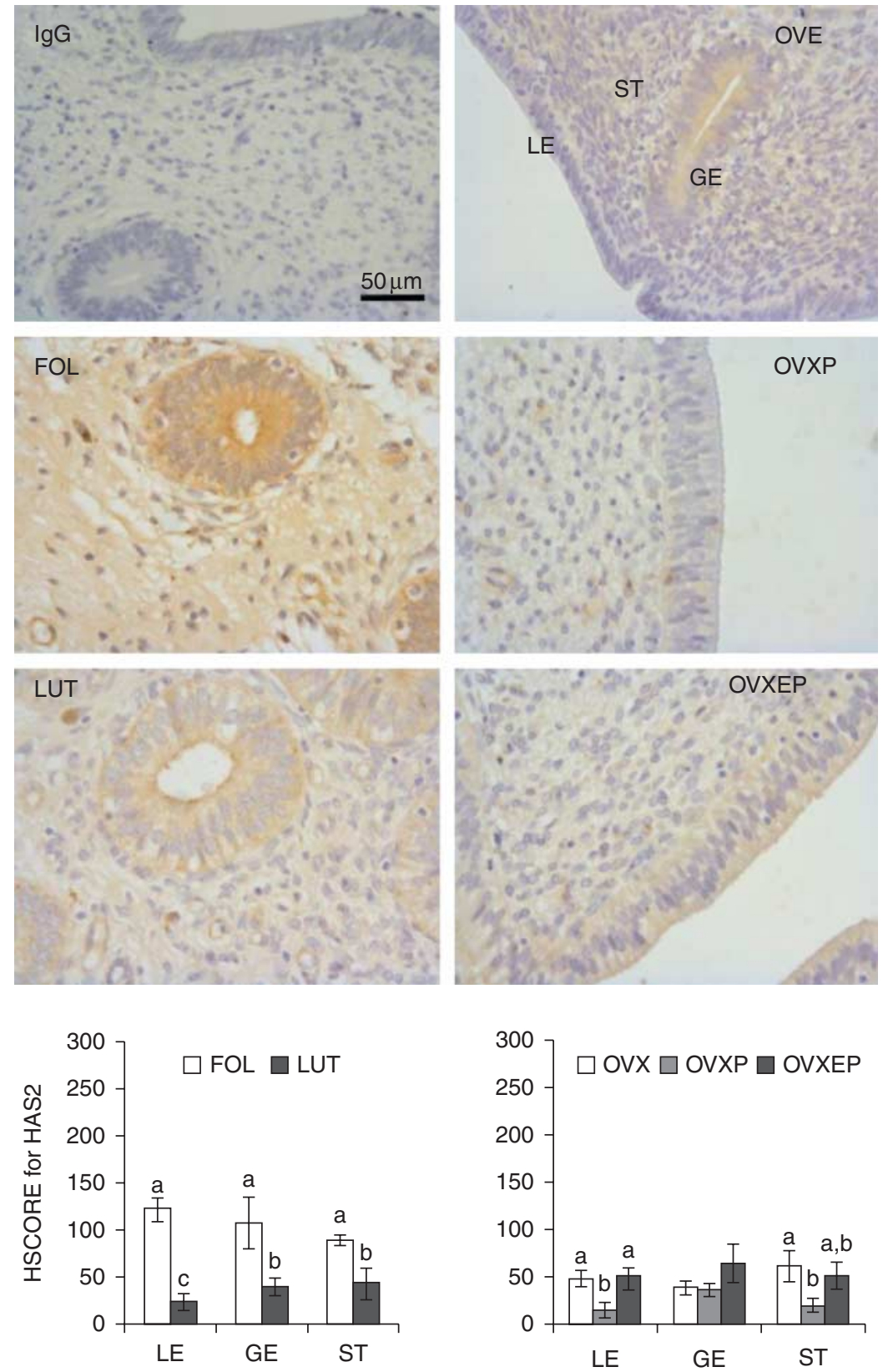

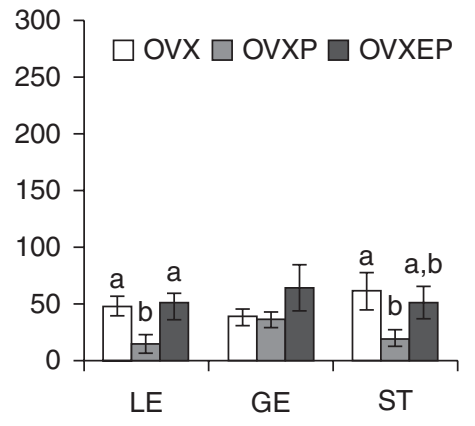

Figure 2 Immunohistochemical localization and quantification of HAS2 in the uterine endometrium in sheep at the follicular (FOL) and luteal (LUT) stages of the estrous cycle (left panels) and in ovariectomized ewes treated with vehicle $(\mathrm{OVX})$, progesterone (OVXP), or estradiol and progesterone (OVXEP) (right panels). HAS2 is shown as brown staining (DAB) while nuclei are counterstained with hematoxylin. The HSCORE is shown as mean \pm S.E.M. Bars with different superscripts within the same layer are significantly different at ${ }^{\text {a vs } b} P \leq 0.05$ or ${ }^{\text {a vs }}{ }^{\mathrm{c}} P<0.01$. expression at the gene and protein levels in parallel with the measurement of HA content and molecular weight.

By qPCR analyses, we showed that HAS1 mRNA expression is affected neither by the stage of estrous cycle nor by steroid treatments of ovariectomized animals for 10 days $(P>0.05)$. However, HAS1 expression tended to be lower in LUT when compared with FOL animals $(P=0.09)$. To our knowledge, there are no previous reports comparing HAS expression in the endometrium during different stages of the estrous cycle. In agreement with our results, HAS1 mRNA expression was shown to decrease in the uterine region of the cervix at the LUT phase of the estrous cycle in sheep compared with the FOL phase (pre-LH surge) (Perry et al. 2010b). In mice, although HAS1 mRNA expression was not different in the cervix of pregnant (day 15) vs nonpregnant animals, treatment of cervical fibroblasts with progesterone in vitro for $6 \mathrm{~h}$ resulted in a significant reduction of HAS1 expression in vitro (Uchiyama et al. 2005). HAS1 mRNA expression was not different among ovariectomized animals. However, at the protein level, immunostaining showed significant reduction of HAS1 protein in GE and ST in OVXP and OVXEP compared with OVX ewes. This suggests that HAS1 mRNA expression may only be affected when tissue is exposed to progesterone for short periods and this effect 

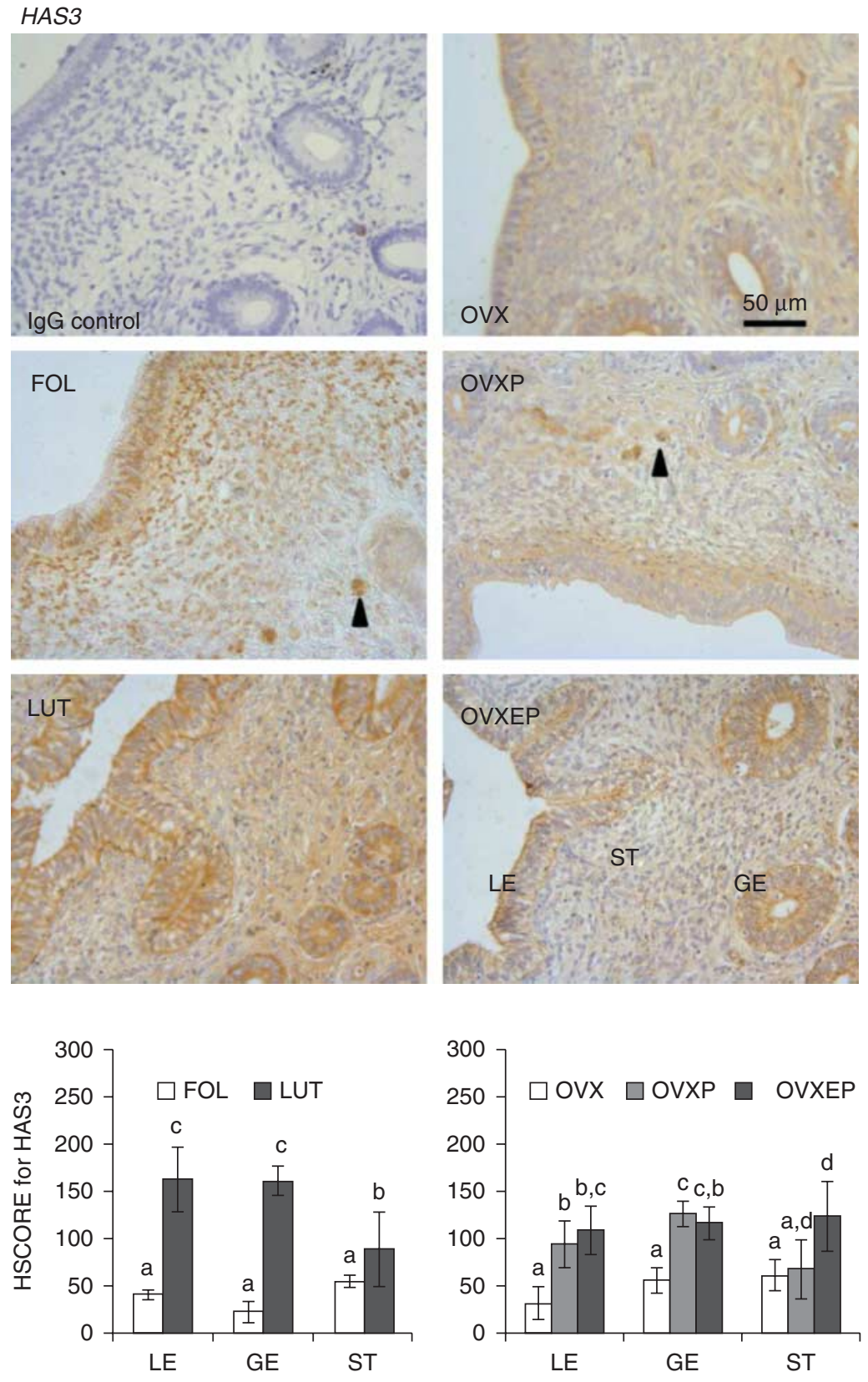

Figure $3 \mathrm{Imm}$ mohistochemical localization and quantification of HAS3 in the uterine endometrium in sheep at the follicular (FOL) and luteal (LUT) stages of the estrous cycle (left panels) and in ovariectomized ewes treated with vehicle (OVX), progesterone (OVXP), or estradiol and progesterone (OVXEP) (right panels). HAS3 is shown as brown staining (DAB) while nuclei are counterstained with hematoxylin. The HSCORE is shown as mean \pm s.E.M. Different letters a vs $b$ indicate a trend $(P<0.1)$ while a vs $c$ or a vs $d$ indicate significant difference at $P<0.05$ within the same layer. Immune cells, mostly lymphocytes (indicated by black arrows) were extracted from the image before the quantification. is not maintained after an extended treatment with progesterone for 10 days. A similar discrepancy in expression of HAS mRNA and HAS protein was also reported in earlier studies (Nykopp et al. 2009).

The highest HAS2 mRNA expression was observed in the FOL group, which was significantly higher than that in the LUT group. Progesterone appears to reduce the expression of HAS2 only when plasma estrogen levels are not high. Treatment of OVX ewes with progesterone significantly reduced HAS2 expression $(P=0.038)$, while in the presence of a high estrogen concentration in the OVXEP group, the effect of progesterone was not significant. Progesterone was shown to inhibit expression of HAS2 mRNA in uterine cervix in the absence of estrogen (Uchiyama et al. 2005). In contrast, high estradiol induced expression of HAS2 in the ovulatory follicles (Schoenfelder \& Einspanier 2003). Here, we show that these two steroids have diverse effects on expression of HAS2 in the uterine endometrium where high estradiol during $\mathrm{FOL}$ the phase stimulates HAS2 expression and the high progesterone during the LUT phase downregulates its expression.

HAS3 mRNA in the LUT was significantly higher phase $(P<0.01)$ compared with the FOL phase, suggesting that progesterone upregulates HAS3 synthesis. This was confirmed by IHC where a significant increase in 

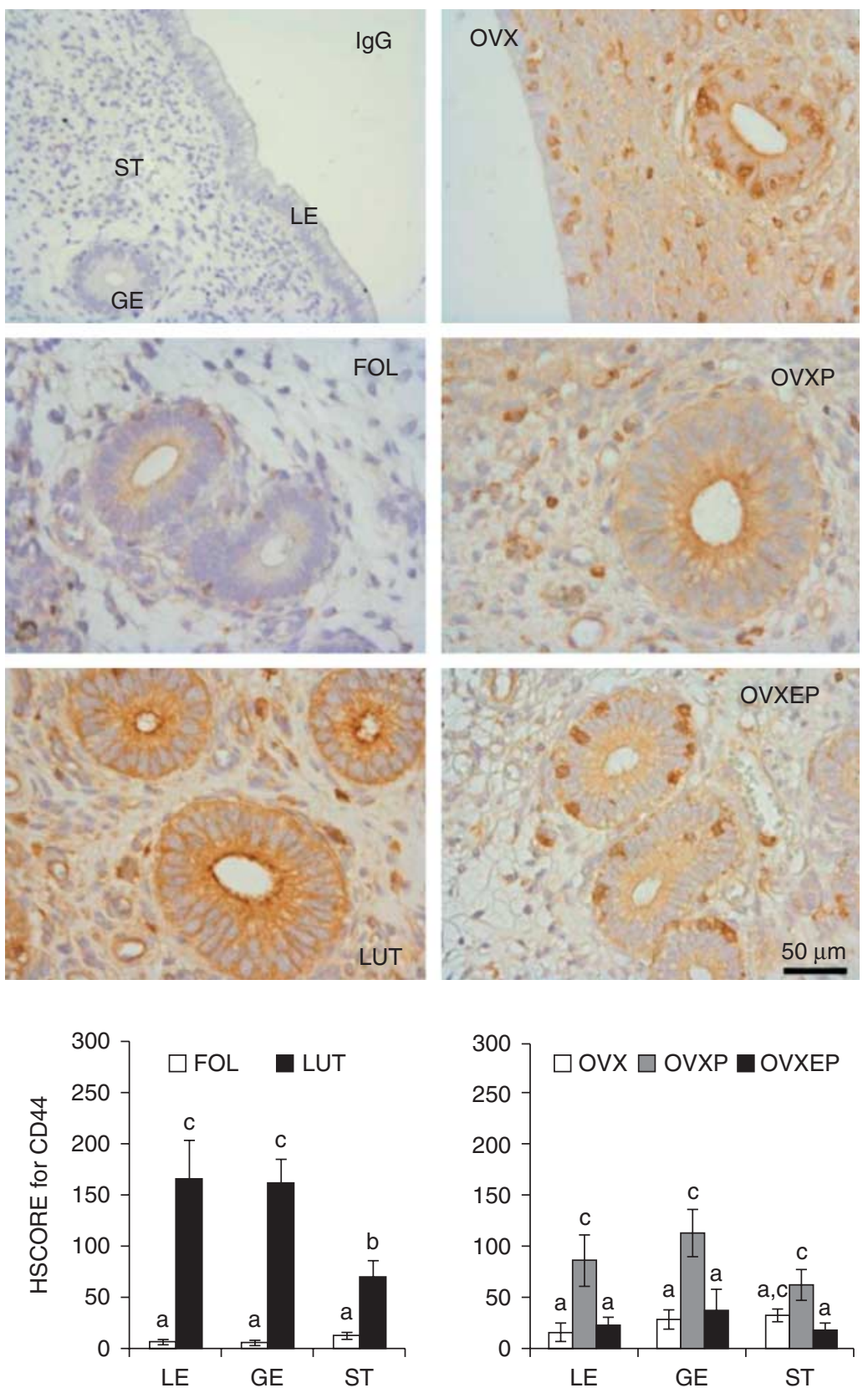

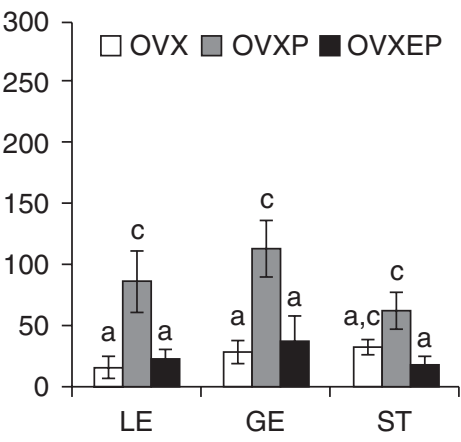

Figure 4 Immunohistochemical localization and quantification of $C D 44$ in the uterine endometrium in sheep at the follicular (FOL) and luteal (LUT) stages of the estrous cycle (left panels) and in ovariectomized ewes treated with vehicle (OVX), progesterone (OVXP), or estradiol and progesterone (OVXEP) (right panels). CD44 is shown as brown staining (DAB) while nuclei are counterstained with hematoxylin. The HSCORE is shown as mean \pm S.E.M. Bars with different superscripts within the same layer are significantly different at

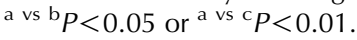

HAS3 staining was observed in GE and LE in the endometrium of the LUT group compared with the FOL group as well as in all endometrial layers of the OVXP and OVXEP groups compared with the OVX group. In accordance with these results, HAS3 mRNA expression was higher in uterine cervix at day 15 of pregnancy compared with non-pregnant mice and treatment of cervical fibroblasts with progesterone resulted in increased HAS3 expression (Uchiyama et al. 2005). It is perhaps paradoxical that the level of HAS3 mRNA expression was increased in LUT vs FOL groups but was lower in the OVXP and OVXEP groups compared with the OVX group. This may be attributed to the duration of progesterone administration, which lasted for 10 days in the OVXP and OVXEP groups. Previous studies have shown that LE and GE exhibit downregulation of progesterone nuclear receptors by days 11 and 13 of the cycle respectively (Spencer \& Bazer 2002), which is associated with changes in the functions of the endometrium. Wathes et al. (1996) reported downregulation of progesterone receptors in the LE and superficial gland at all time points when ovariectomized ewes were treated with progesterone for $8,10,12$, or 14 days. We also observed downregulation 

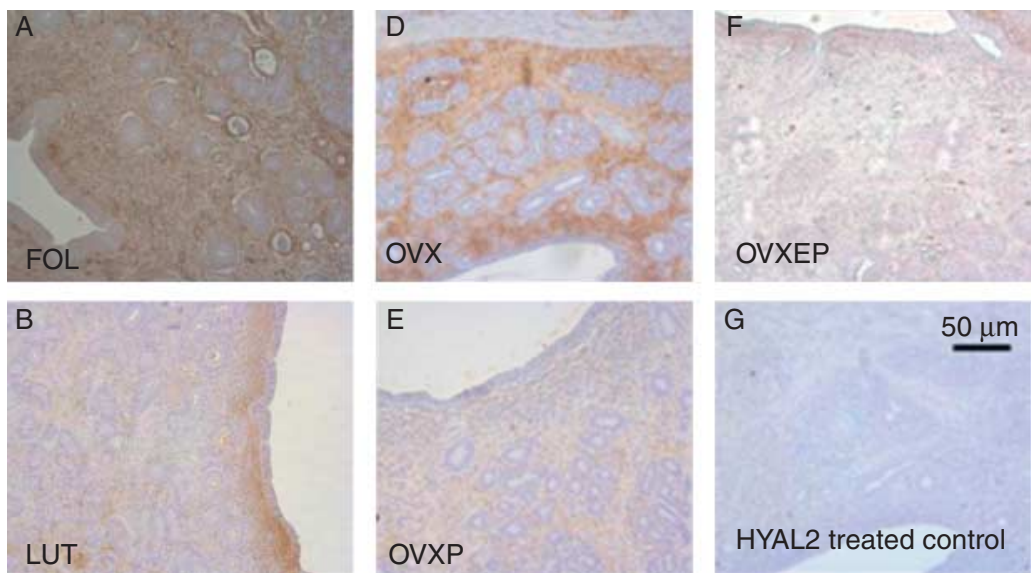

C

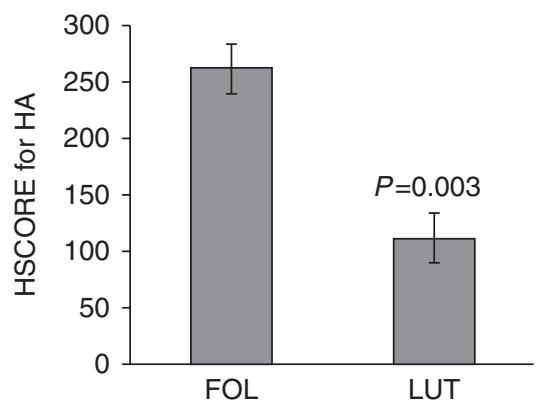

$\mathrm{H}$

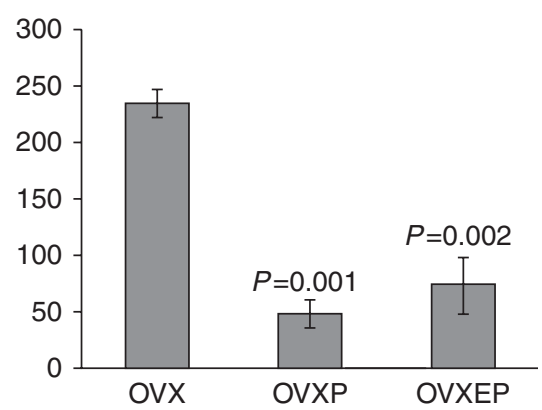

Figure 5 Immunohistochemical localization and quantification of $H A$ in the uterine endometrium in sheep at the follicular (FOL; A) and luteal (LUT; B) stages of the estrous cycle and in ovariectomized ewes treated with vehicle (OVX; D), progesterone (OVXP; E), or estradiol and progesterone (OVXEP; F). HA is shown as brown staining (DAB) while nuclei are counterstained with hematoxylin. The HSCORE is shown as mean \pm S.E.M. $P$ values are shown compared with the FOL (C) or OVX $(\mathrm{H})$ groups. of progesterone nuclear receptors in the OVXP and OVXEP groups compared with the OVX group in the present experiment (data not shown) and this may explain the difference in HAS3 expression pattern. However, HAS3 protein expression was increased in the endometrium under progesterone dominance in both the LUT and OVXP groups and it is known that HAS3 mRNA expression is sometimes not correlated with HAS3 immunoreactivity (Nykopp et al. 2010).

$\mathrm{HA}$ has a high rate of turnover at both the cellular and the tissue levels mainly due to enzymatic hydrolysis by HYALs that include HYAL1, HYAL2, HYAL3, HYAL4, HYALP1, and PH-20. Predominantly, HYAL1 and HYAL2 are considered the major HA-degrading enzymes in somatic tissue (Bastow et al. 2008). Moreover, HYAL2 is a cell surface receptor of endogenous Jaagsieket sheep retrovirus, which is proposed to partake in the fusion of binucleate giant cells and LE (Bazer et al. 2010) during implantation. HYAL2 cleaves HMW HA into biologically active fragments of 20-30 kDa or 50 disaccharide units whereas HYAL1 has the capacity to digest to smaller fragments, mainly tetrasaccharides (Stern 2004). In this study, HYAL1 and HYAL2 mRNA were not affected by the stage of the estrous cycle. In addition, HYAL1 was not affected by progesterone and estrogen treatment of OVX animals. In contrast, very high levels of HYAL2 were observed in the OVX group (about 60000 copies compared with $\sim 30000$ in intact animals). This was reduced by progesterone administration in the presence or absence of estrogen to the levels observed in the intact animals, suggesting that HYAL2 expression is regulated by ovarian steroids. HYAL2 has been reported to be a specific marker for endometrial cancer (Paiva et al. 2005). HA oligosaccharides resulting from HA depolymerization by HYAL2 were found to enhance cell proliferation and make tissue prone to cancer development or facilitate the progression and metastasis of an already established cancer, possibly by angiogenesis (Toole 2004). It was previously reported that administration of steroids reduces the incidence of endometrial cancer in women (Tawil et al. 1973, Wang et al. 2009, Yoffou et al. 2011). This could be mediated by the steroid-induced downregulation of HYAL2 as shown in the OVXP and OVXEP groups compared with the OVX group. Sunil et al. (2000) reported that progesterone, either singly or in combination with estradiol, reduced the activity of HYAL in the mammary gland of an ovariectomized rat.

We have evaluated the HA distribution by IHC using HABP and quantified the results with HSCORE. Although all HAS were variably detectable in ST as well as LE and GE of the endometrium, HA immunostaining was rather localized within the ST. This may be due to the release of the HA produced by LE and GE into the uterine lumen. HA localization in the ST was also shown in the mouse (Gomes et al. 2009) and human endometrium 

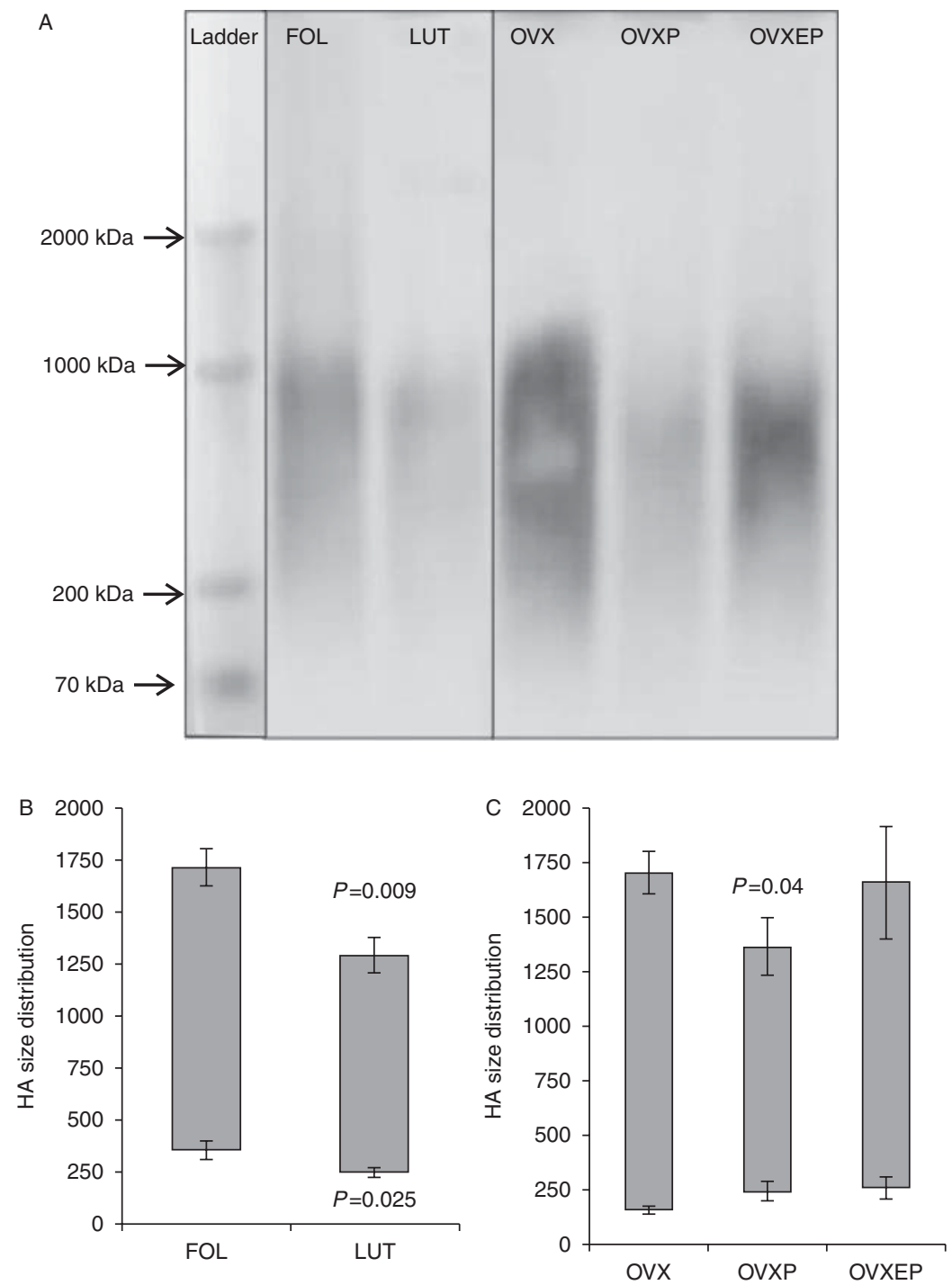

Figure 6 (A) Estimation of HA molecular weight distribution by b-HABP and HRP-antibiotin IgG (representative blot). The molecular weight of the HA was determined with Alfa Ease FC software using HA standards shown to the left of the gel for reference. (B) The highest and lowest molecular weight of HA in endometrium collected from intact ewes at the follicular (FOL) and luteal (LUT) phases of the estrous cycle, and (C) ovariectomized ewes treated with vehicle (control; OVX), progesterone (OVXP) or estrogen and progesterone (OVXEP). Data are from six independent repeats and presented as mean \pm s.E.M. in a box plot. $P$ values are shown as compared with the FOL group or OVX group.
(Afify et al. 2006, Nykopp et al. 2010). In this study, the level of HA was drastically increased in the absence of high plasma progesterone as seen in the FOL and OVX groups. Results of analyses of the kinetic (apparent $K(\mathrm{~m})$ values) of different HAS isoforms for the two substrates, UDP-GIcNAc and UDP-GIcUA, were previously shown to differ (Itano et al. 1999). Recombinant HAS1 protein was shown to exhibit a lower rate of synthesis of HA matrix around cells (Tammi et al. 2002). HAS2 was proposed to be the major producer of HA (McDonald \& Camenisch 2003). These facts may explain the intense HA immunostaining observed in the FOL and OVX groups (which we found to have high HAS2 expression) compared with the less-intense staining in the LUT as well as in the OVXP and OVXEP groups (with lower HAS2 expression).

In previous reports, kinetic studies demonstrated that HAS proteins are distinct from each other in enzyme stability and elongation rate of HA (Stern et al. 2006). Analysis of the size distributions of HA generated by recombinant HAS proteins demonstrated that HAS3 synthesized smaller HA with a molecular mass of $0.1 \times$ $10^{6}$ to $1 \times 10^{6} \mathrm{Da}$, shorter than those synthesized by HAS1 $\left(0.2-2 \times 10^{6} \mathrm{Da}\right)$ and HAS2 $\left(>2 \times 10^{6} \mathrm{Da}\right)$ (Itano et al. 1999). It is worth emphasizing that prediction of the biological effect mediated by the changes in the synthetic rates of HA produced by either HAS1, -2, or -3 is quite difficult unless the degradation pathways brought about by HYAL (s) are also taken into consideration. In this study, we analyzed HA extracted from endometrial samples from different experimental groups using agarose gel electrophoresis to examine the molecular size distribution of the HA produced. We found that the largest size of HA in the LUT group was significantly lower than that observed in the FOL group. A similar result was noticed in OVXP ewes, which showed reduced maximum size of HA compared with OVX ewes. The smallest size of HA was also observed in the LUT group. These results clearly show that endometrial samples collected from animals under 
high plasma progesterone levels, which show higher HAS3 protein expression, exhibit smaller HA compared with those collected from FOL and OVX animals having lower progesterone plasma concentrations. The presence of high estrogen showed a tendency to increase HA size in the OVXEP when compared with the OVXP group. This is not surprising as estrogen resulted in a tendency to increase HAS2 mRNA expression compared with the OVXP group.

The functions of HMW HA molecules include hydration, space filling, anti-angiogenesis, immunosuppression, impedance of differentiation, and cell cycle arrest. These functions usually depend on the physical properties of the individual HA molecule (Stern et al. 2006). On the other hand, LMW HA molecules are known to be pro-inflammatory, angiogenic, and antiapoptotic and facilitate cell-to-cell interaction and cell proliferation and are mediated by receptor signaling (Stern et al. 2006). CD44 is a predominant cell surface HA receptor (Singh et al. 2010). Most effects of HA on cell phenotype and biological processes such as adhesion, migration, proliferation, and angiogenesis involve HA-CD44-mediated signaling and cytoskeleton reorganization (Fujita et al. 2002, Bourguignon 2008). The signaling functions of $C D 44$ have been extensively studied and well documented in the literature (Ponta et al. 2003, Toole 2004). Several signaling transduction pathways are initiated when various sizes of HA fragments bind to CD44 (Stern et al. 2006). In this study, we have shown that high plasma estrogen (in the FOL group) is associated with significantly lower CD44 mRNA expression in ovine endometrium compared with the LUT group, which was clearly reflected in CD44 staining by IHC. Progesterone administration significantly increased CD44 mRNA expression compared with the OVX ewes. This effect was completely abolished in the OVXEP group in the presence of estrogen. However, IHC staining showed significant difference in CD44 protein expression among OVX, OVXP, and OVXEP groups. This suggests that a high-estrogen, lowprogesterone hormonal profile (as in the FOL group) will inhibit CD44 expression. Several studies have shown that LMW HA-CD44 interaction can induce intriguingly complex signaling transduction involving focal adhesion kinase, proto-oncogene tyrosine-protein kinase (Src), and MAPK3/1 in both health and disease (Toole 2004, Slevin et al. 2007, Matou-Nasri et al. 2009, Wang et al. 2011). In this study, it was obvious that LMW HA and CD44 were prominent under conditions of progesterone dominance in sheep endometrium, whereas HMW HA and less CD44 were observed with estrogen. Collectively, it can be inferred that the larger HA produced by HAS2 in an estrogen-dominant environment is associated with low CD44 expression and is thus required for functions that are not dependent on receptor-mediated signaling. In contrast, smaller HA molecules produced by HAS3 in a progesterone-dominant environment are associated with and possibly dependent on CD44 signaling to convey some biological functions of progesterone in preparation for endometrial receptivity for embryo implantation. This notion is currently under further investigation in our laboratory and is strengthened by the observation that CD44 staining in human endometrial ST occurs during a period when the endometrium is most receptive to embryo implantation (Afify et al. 2006) and during early stages of embryo development in cattle (Furnus et al. 2003) and human (Campbell et al. 1995). In conclusion, our results show that the level of HA production and the molecular weight of $\mathrm{HA}$ in the endometrium are partly regulated by ovarian steroids through differential expression of different HAS both at the gene and protein levels.

\section{Materials and Methods}

\section{Chemicals and reagents}

All chemicals and reagents were purchased from Sigma Chemical Company unless otherwise stated.

\section{Experimental procedure and animal treatments}

All experimental procedures complied with regulations in the UK Animal (Scientific Procedures) Act, 1986. Thirty healthy, proven fertile, non-pregnant Welsh Mountain adult ewes were housed indoors with straw bedding. They were fed with hay and concentrate diet. Water was provided and animals were allowed to drink ad libitum. Eight ewes were kept intact while 22 ewes were ovariectomized. The intact ewes $(n=8)$ were synchronized using intravaginal Chronogest sponge (Intervet UK Ltd, Cambridge, UK) for 11 days and treated with 200 IU PMSG (Intervet UK Ltd, Buckinghamshire, UK) i.m. at the time of sponge removal. Estrous was observed $24 \mathrm{~h}$ after sponge removal. The intact ewes were killed on day 9 (mid-LUT phase; $n=5$ ) or on day 16 (FOL phase; $n=3$ ) of the synchronized estrous cycle. Blood samples were collected at the time of killing of intact animals. Simultaneously, 22 ewes were ovariectomized as described by Jackson (2004). To eliminate the effect of endogenous gonadotropins ( $\mathrm{LH}$ and FSH), ewes received Buserelin acetate (gonadotropin agonist; Surefact, Aventis Pharma Ltd, Kent, UK) during the entire period of study administered continuously by an osmotic pump (ALZET model, DURECT Corp, Cupertino, US), which was inserted subcutaneously in the forelimb at the time of ovariectomy. These pumps contained $2 \mathrm{mg}$ Buserelin in $2 \mathrm{ml}$ normal saline and are designed to secrete $2.5 \mu \mathrm{l} / \mathrm{h}$ for 28 days. After a recovery period of 8 days, the ovariectomized ewes were treated i.m. daily with one of the three treatments: i) $2 \mathrm{ml}$ corn oil (which was used as a vehicle for delivery of progesterone and estradiol) for 10 days (OVX, $n=6)$, ii) $25 \mathrm{mg}$ progesterone for ten successive days (OVXP, $n=7$ ), and iii) $6 \mu \mathrm{g}$ estradiol benzoate and $25 \mathrm{mg}$ progesterone for 3 days followed by progesterone only (25 mg) for 7 days (OVXEP, $n=8$ ). Blood samples were collected every other day from the day of commencement of treatments; plasma was separated and stored at $-20{ }^{\circ} \mathrm{C}$ until assayed for progesterone and estradiol. Ewes were killed $24 \mathrm{~h}$ after the last 
injection of the steroid treatment. Uteri were harvested; small pieces of the caruncular and intercaruncular regions of endometrium of the uterine horn were finely dissected, snap-frozen, and kept at $-80{ }^{\circ} \mathrm{C}$ for gene expression analysis. Transverse sections of the uterine horns were fixed in $4 \%$ formalin (BDH, Poole, UK) and later embedded in paraffin for IHC.

\section{Measurement of progesterone and estradiol in plasma samples}

Plasma progesterone concentrations were determined using ELISA kits (Ridgeway Science, Cirencester, UK) following manufacturer's instructions. Standards ranged from 0.5 to $20 \mathrm{ng} / \mathrm{ml}$ and were prepared in charcoal-stripped sheep plasma. Plasma estradiol concentrations were determined by RIA as described previously (Robinson et al. 2002). The intraassay coefficient of variation was $3.2 \%$. No interassay coefficient was calculated as all samples were analyzed in a single assay.

\section{RNA isolation and RT}

For total RNA isolation, frozen tissue samples ( $200 \mathrm{mg})$ were homogenized in TRI reagent followed by standard RNA extraction procedure using chloroform. To achieve better purity, all RNA samples were cleaned through RNeasy Mini Kit columns (Qiagen Ltd) following the RNA Clean-up protocol supplied by the manufacturer. The concentration and purity of the isolated RNA samples were determined using a NanoDrop ND-1000 spectrophotometer (NanoDrop Technologies, Inc., Wilmington, DE, USA). All samples had an A260:280 ratio of absorbance between 1.9 and 2.1. The integrity of the RNA was confirmed by running it on a $2 \%$ agarose gel to visualize the $18 \mathrm{~S}$ and $28 \mathrm{~S}$ rRNA bands. Total RNA (500 ng) from each sample was then treated for potential genomic DNA carryover in a single reaction in accordance with guidelines supplied by Promega Corporation. DNase-treated RNA was reverse transcribed using random hexamer primers and processed accordingly (Reverse Transcription System Kit; Promega).

\section{Primer design, optimization, and qPCR}

Gene transcripts were quantified by real-time PCR as described previously (Fenwick et al. 2008, Wathes et al. 2011) with some modifications. Bovine nucleotide sequences derived from the coding domain sequence of the genes of interest and housekeeping genes were obtained directly from the GenBank published in the National Centre for Biotechnology Information database (NCBI, Bethesda, MD, USA) and their individual details are supplied in Table 3. For each gene, the primers were tested by conventional PCR amplification using a Multiplex PCR kit (Qiagen), $25 \mathrm{ng}$ CDNA and $0.5 \mu \mathrm{M}$ primers. The optimal annealing temperature (resulting in minimal threshold cycle $(C t))$ was determined using the temperature gradient function of the real-time PCR machine (qPCR, CFX 96 Real-Time PCR Detection System, Bio-Rad Laboratories, Inc.) using a set of eight identical reactions for each primer. A melting curve analysis was performed for each amplicon between 50 and $95{ }^{\circ} \mathrm{C}$ and as such any smaller non-specific products such as dimers were melted (if present) before fluorescence acquisition (Table 3). External standards were prepared as described previously (Fenwick et al. 2008) from CDNA as identical to real-time PCR products and purified using QIAquick PCR purification columns (Qiagen) and the presence of a single product was confirmed by electrophoresis on a $2 \%$ $(w / v)$ agarose gel.

Copy number standards were then generated as described previously by Clemente et al. (2009). Briefly, the precise concentration of purified PCR product was determined using the NanoDrop ND-1000 spectrophotometer (NanoDrop Technologies, Inc.) and the copy numbers of fragments were

Table 3 Oligonucleotide primer sequences and amplicon sizes and their corresponding annealing and plate-reading temperatures used for the qPCR assays.

\begin{tabular}{|c|c|c|c|c|c|}
\hline Gene & Primer sequence $\left(5^{\prime}-3^{\prime}\right)$ & Size (bp) & Accession no. & $\begin{array}{c}\text { Annealing } \\
\text { temperature }\left({ }^{\circ} \mathrm{C}\right)\end{array}$ & $\begin{array}{c}\text { Reading } \\
\text { temperature }\left({ }^{\circ} \mathrm{C}\right)\end{array}$ \\
\hline HAS1 & $\begin{array}{l}\text { F: GGTACAACCAGAAGTTCCTGGG } \\
\text { R: CGGAAGTACGACTTGGACCAG }\end{array}$ & 184 & AB017803.1 & 61 & 82 \\
\hline HAS2 & $\begin{array}{l}\text { F: GGGGGAGATGTCCAGATTTT } \\
\text { R: ATGCACTGGACACATCCGA }\end{array}$ & 125 & NM174079 & 61 & 74 \\
\hline HAS3 & $\begin{array}{l}\text { F: ACAGGTTTCTTCCССТTCTTCC } \\
\text { R: GCGACATGAAGATCATCTCTGC }\end{array}$ & 166 & NM001192867.1 & 61 & 78 \\
\hline$C D 44$ & $\begin{array}{l}\text { F: TATAACCTGCCGATATGCAGG } \\
\text { R: CAGCACAGATGGAATTGGG }\end{array}$ & 221 & NM174013.3 & 61 & 80 \\
\hline HYAL1 & $\begin{array}{l}\text { F: TCAGCCTTGAGGTTTCCCTA } \\
\text { R: TCCAGATGGTAGTGAAGGGC }\end{array}$ & 144 & NM001017941.1 & 61 & 78 \\
\hline HYAL2 & $\begin{array}{l}\text { F: GGACTCCCACACAGTTCCTG } \\
\text { R: ACССTCGTTAGGTGAAGCCT }\end{array}$ & 280 & NM174347.2 & 59 & 84 \\
\hline$B 2 M$ & $\begin{array}{l}\text { F: CGCCAGAAGATGGAAAGC } \\
\text { R: GAACTCAGCGTGGGACAGA }\end{array}$ & 167 & NM001009284.1 & 59 & 76.5 \\
\hline GAPDH & $\begin{array}{l}\text { F: CACTGTCCACGCCATCACT } \\
\text { R: GCCTGCTTCACCAССТTCT }\end{array}$ & 267 & NM001190390.1 & 63.3 & 82.5 \\
\hline $18 S$ & $\begin{array}{l}\text { F: GCTCGСТССТСТССТАСТTG } \\
\text { R: CGTTTCTCAGGСTCССТСT }\end{array}$ & 326 & AY753190.1 & 59 & 83 \\
\hline HPRT1 & $\begin{array}{l}\text { F: AGCGTGGTGATTAGCGATG } \\
\text { R: CAACAGGTCGGCAAAGAAC }\end{array}$ & 219 & NM001034035.1 & 61.4 & 76.5 \\
\hline
\end{tabular}


empirically determined using the following equation: copy number of PCR standard=(amount of CDNA (in ng) $\times$ Avogadro Constant)/(PCR product size (in bp) $\times 1 \times 10^{9} \times 660$ ) where Avogadro Constant $=6.022 \times 10^{23}$ ). Standards containing $10^{7}-10^{0}$ copies/PCR were then prepared by tenfold serial dilutions. The standards in duplicates and cDNA samples (equivalent to $25 \mathrm{ng}$ reverse transcribed RNA) were then amplified in the same reaction prepared from a master mix containing KAPA SYBR green mix (Anachem, Boston, MA, USA), forward + reverse primer $\operatorname{mix}(20 \mu \mathrm{M})$, and nuclease-free water in $20 \mu \mathrm{l}$ reactions. No-template controls (NTC) and RT-negative controls were included on every plate for each gene product. To minimize variation, all samples included in each analysis were derived from the same RT batch, prepared under the same conditions, and were analyzed on a single plate in duplicate. Ct values for unknowns and standards were obtained using a real-time PCR machine (qPCR, CFX 96 RealTime PCR Detection System, Bio-Rad Laboratories, Inc.). Absolute starting quantities (in copy numbers) were calculated by comparing the $C t$ values of the unknown samples to the standard curve using the CFX Manager Software Version 1.0.1035.131 (Bio-Rad Laboratories, Inc.). Efficiency of the assays (E) was $\geq 95 \%$, and standard curve $R^{2}$ was $\geq 0.999$. Gene expression results were normalized using geNorm software using data from the reference genes - B2M and $G A P D H$. The pattern of gene expression for target genes was similar in caruncular and intercaruncular regions of the endometrium, and data from the two regions were pooled.

\section{Immunohistochemistry}

Protein expression for HAS1, HAS2, HAS3, and CD44 was determined by IHC. Paraffin-embedded uterine sections $(5 \mu \mathrm{m})$ mounted on superfrost slides (VWR International Co., Leicestershire, UK) were dewaxed, rehydrated, and immersed in boiling-hot sodium citrate solution $(2.947 \mathrm{~g} / \mathrm{l} \mathrm{pH}$ 6.0) for $30 \mathrm{~min}$. Slides were then rinsed in Tris-buffered saline, $\mathrm{pH}$ 7.6, containing $0.1 \%$ Triton-X ( $/ \mathrm{v})$. Non-specific binding was blocked by incubating sections with $10 \%(\mathrm{v} / \mathrm{v})$ normal goat serum (Dako, Glostrup, Denmark) in TBS containing 1\% (w/v) BSA for $2 \mathrm{~h}$ in a humidified chamber. Without washing, sections were incubated with primary antibodies: either polyclonal rabbit anti-HAS1 $(5 \mu \mathrm{g} / \mathrm{ml}$; MCA1730; Abgent, Inc., San Diego, CA, USA), polyclonal rabbit anti-HAS2 (4 $\mu \mathrm{g} / \mathrm{ml}$; Sc-66916; Santa Cruz Biotechnology, Inc.), polyclonal rabbit anti-HAS3 (4 $\mu \mathrm{g} / \mathrm{ml}$; Sc-66917; Santa Cruz), or monoclonal mouse anti-CD44v6 (AP4928C; $10 \mu \mathrm{g} / \mathrm{ml} ;$ AbD Serotec, Kidlington, Oxford, UK). The slides were incubated in a humidified chamber at $4{ }^{\circ} \mathrm{C}$ overnight. On the following day, the slides were rinsed in TBS and endogenous peroxidase was blocked using peroxidase suppressor (Thermo Scientific, Rockford, IL, USA) for $45 \mathrm{~min}$. The primary antibody was detected using biotinylated anti-rabbit secondary antibody (1:100) or anti-mouse and Vectorstain $\mathrm{ABC}$ method according to the manufacturer's instructions (Vector Laboratories, Peterborough, UK), which was followed by visualization using diaminobenzidine (DAB; Vector Laboratories). The sections were counterstained with hematoxylin, dehydrated in graded ethanol, and then Histoclear. The sections were mounted with DPX, coverslipped, and visualized under an Olympus BX60 microscope (Olympus, Essex, UK). Negative controls were treated in the same way except that the primary antibody was replaced with normal rabbit (for HAS1-3) or normal mouse (for CD44) IgGs (Santa Cruz Biotechnology, Inc.).

\section{HA immunostaining}

For staining of HA in tissue sections, sections were dewaxed and dehydrated and blocked as for IHC. Sections were then incubated with b-HABP (AMBS Biotechnology, Oxon, UK) at $2.5 \mu \mathrm{g} / \mathrm{ml}$ concentration overnight at $4{ }^{\circ} \mathrm{C}$ followed by streptavidin-biotinylated HRP (1:200 in PBS; GE Healthcare, Buckinghamshire, UK), for $1 \mathrm{~h}$ at room temperature. Immunostaining was visualized with DAB. Control sections were treated with HYAL2 and washed before staining.

\section{Semiquantitative analysis of immunostaining}

Immunostaining was semiquantitatively assessed using a histochemical score (HSCORE) system. This obtained a score range from 0 to 300 by multiplying the intensity of the stains (score 0-3) and the percentage of area stained (0-100) as described previously (Ponglowhapan et al. 2008). The estimate was based on five random fields per section from all the animals in each treatment group. Images were scored by two independent experienced assessors blinded to the corresponding experimental groups under scoring.

\section{HA extraction and determination of HA molecular size}

Caruncular and intercaruncular pieces of endometrium that were snap-frozen the time of tissue collection were digested for 16-18 $\mathrm{h}$ in $0.1 \mathrm{M}$ sodium acetate buffer, $\mathrm{pH}$ 5.8, containing $0.25 \mathrm{mg} / \mathrm{ml}$ papain (Roche Applied Science), $5 \mathrm{mM}$ EDTA, and $5 \mathrm{mM}$ L-cysteine hydrochloride (anhydrous) at $60^{\circ} \mathrm{C}$ as described previously (Pitsillides et al. 1999).

HA molecular weight distribution was determined using agarose gel electrophoresis according to the principle described in earlier studies (Bjornsson 1993; Lee \& Cowman 1994). The detection method was developed and optimized in our laboratory. It involved mixing digested endometrial samples or HA standards (mixture of 70, 250, 1000 and 2000 kDa Select HA, Hyalose L.L.C., Oklahoma, USA) with loading buffer (TAE buffer containing 20\% v/v glycerol and $0.02 \% \mathrm{w} / \mathrm{v}$ Bromophenol Blue). This was followed by electrophoresis on a $1 \%$ agarose gel for $90 \mathrm{~min}$ at $80 \mathrm{~V}$. Separated HA samples were then transferred onto positively charged nylon membrane (Hybond $\mathrm{N}+$, GE Healthcare, Amersham, Buckinghamshire, UK) by Upward Capillary Transfer overnight using TAE buffer. Membrane blots were blocked in blocking buffer $(10 \%$ (w/v) nonfat dried milk in PBSTween for $2 \mathrm{~h}$ at room temperature). For specific detection of $\mathrm{HA}$, membranes were incubated with b-HABP $(0.08 \mu \mathrm{g} / \mathrm{ml}$ in PBS containing 5\% BSA w/v) for $100 \mathrm{~min}$ at room temperature. Membranes were then washed and incubated with HRPconjugated antibiotin antibody (1:4000; Cell Signaling Technology, Inc., Danvers, US) in PBS-T for 2 h. Membranes were thoroughly washed three times on a shaker at maximum speed 
in PBS-T and then developed using the ECL (ECL-plus) detection system (GE Healthcare). Images were acquired using the chemiluminescence application in the Syngene Gel doc facility (SYNGENE, Cambridge, UK). Analysis of HA size distribution was done with AlphaEase FC software using bands corresponding to the Select HA standards as reference. HA size analysis followed the same pattern in caruncular and intercaruncular regions of the endometrium, and data from the two regions were pooled.

\section{Statistical analysis}

In all the experiments, the data were from at least three animals per experimental group. All data, gene and protein expression, $\mathrm{HA}$ immunostaining, as well as HA molecular weights were analyzed using IBM SPSS (version 19) by independent t-test (to compare LUT with FOL groups) or one-way ANOVA (to compare OVXP and OVXEP with OVX group). If the main treatment effect was significant in ANOVA, Bonferroni post hoc tests were performed. Differences of $P$ values $\leq 0.05$ were considered as significant, while $P$ values $>0.05$ to $<0.1$ were considered as a trend. Data are shown as mean \pm s.E.M.

\section{Declaration of interest}

The authors declare that there is no conflict of interest that could be perceived as prejudicing the impartiality of the research reported.

\section{Funding}

Mr K A Raheem is funded by a PhD scholarship from the Education Trust Fund, Abuja, and Michael Okpara University of Agriculture, Umudike, Nigeria. The studies presented here were funded by a Biotechnology and Biological Sciences Research Council (BBSRC) New Investigator Award to A A Fouladi-Nashta (BB/G008620/1).

\section{References}

Afify AM, Craig S \& Paulino AF 2006 Temporal variation in the distribution of hyaluronic acid, CD44s, and CD44v6 in the human endometrium across the menstrual cycle. Applied Immunohistochemistry \& Molecular Morphology 14 328-333. (doi:10.1097/00129039-200609000-00012)

Aplin JD 2007 Embryo implantation: the molecular mechanism remains elusive. Reproductive Biomedicine Online 14 49-55. (doi:10.1016/ S1472-6483(10)60763-8)

Aruffo A 1996 CD44 one ligand 2 functions. Journal of Clinical Investigation 98 2191-2192. (doi:10.1172/JCI119026)

Aruffo A, Stamenkovic I, Melnick M, Underhill CB \& Seed B 1990 CD44 is the principal cell surface receptor for hyaluronate. Cell 61 1303-1313. (doi:10.1016/0092-8674(90)90694-A)

Babayan A, Neuer A, Dieterle S, Bongiovanni AM \& Witkin SS 2008 Hyaluronan in follicular fluid and embryo implantation following in vitro fertilization and embryo transfer. Journal of Assisted Reproduction and Genetics 25 473-476. (doi:10.1007/s10815-008-9268-4)

Balazs E \& Gibbs D 1970 The rheological properties and the biological function of hyaluronic acid. In Chemistry and Molecular Biology of Intercellular Matrix, vol 3, pp 431-437. Eds EA Balazs. New York: Academic Press.
Bastow ER, Byers S, Golub SB, Clarkin CE, Pitsillides AA \& Fosang AJ 2008 Hyaluronan synthesis and degradation in cartilage and bone. Cellular and Molecular Life Sciences 65 395-413. (doi:10.1007/s00018-0077360-z)

Bazer FW, Wu G, Spencer TE, Johnson GA, Burghardt RC \& Bayless K 2010 Novel pathways for implantation and establishment and maintenance of pregnancy in mammals. Molecular Human Reproduction 16 135-152. (doi:10.1093/molehr/gap095)

Bjornsson S 1993 Size-dependent separation of proteoglycans by electrophoresis in gels of pure agarose. Analytical Biochemistry 210 292-298. (doi:10.1006/abio.1993.1198)

Bourguignon LYW 2008 Hyaluronan-mediated CD44 activation of RhoGTPase signaling and cytoskeleton function promotes tumor progression. Seminars in Cancer Biology 18 251-259. (doi:10.1016/ j.semcancer.2008.03.007)

Camenisch TD, Spicer AP, Brehm-Gibson T, Biesterfeldt J, Augustine ML, Calabro A Jr, Kubalak S, Klewer SE \& McDonald JA 2000 Disruption of hyaluronan synthase-2 abrogates normal cardiac morphogenesis and hyaluronan-mediated transformation of epithelium to mesenchyme. Journal of Clinical Investigation 106 349-360. (doi:10.1172/JCI10272)

Campbell S, Swann HR, Aplin JD, Seif MW, Kimber SJ \& Elstein M 1995 CD44 is expressed throughout pre-implantation human embryo development. Human Reproduction 10 425-430. (doi:10.1093/HUMREP/10.6.1571)

Cidadao AJ, Thorsteinsdottir S \& David-Ferreira JF 1990 Immunocytochemical study of tissue distribution and hormonal control of chondroitin-dermatan-and keratan sulfates from rodents uterus. European Journal of Cell Biology 52 105-116.

Clemente M, de La Fuente J, Fair T, Al Naib A, Gutierrez-Adan A, Roche JF, Rizos D \& Lonergan P 2009 Progesterone and conceptus elongation in cattle: a direct effect on the embryo or an indirect effect via the endometrium? Reproduction 138 507-517. (doi:10.1530/REP09-0152)

Deed R, Rooney P, Kumar P, Norton JD, Freemont AJ \& Kumar S 1997 Early-response gene signaling is induced by angiogenic oligosaccharides of hyaluronan in endothelial cells. Inhibition by non-angiogenic, high-molecular-weight hyaluronan. International Journal of Cancer 71 116-122. (doi:10.1002/(SICI)1097-0215(19970410)71:2<251::AIDIJC21 > 3.0.CO;2-J)

Fenwick MA, Fitzpatrick R, Kenny DA, Diskin MG, Patton J, Murphy JJ \& Wathes DC 2008 Interrelationships between negative energy balance (NEB) and IGF regulation in liver of lactating dairy cows. Domestic Animal Endocrinology 34 31-44. (doi:10.1016/j.domaniend. 2006.10.002)

Fujita Y, Kitagawa M, Nakamura S, Azuma K, Ishii G, Higashi M, Kishi H, Hiwasa T, Koda K, Nakajima N et al. 2002 CD44 signaling through focal adhesion kinase and its anti-apoptotic effect. FEBS Letters 528 101-108. (doi:10.1016/S0014-5793(02)03262-3)

Furnus CC, Valcarcel A, Dulout FN \& Errecalde AL 2003 The hyaluronic acid receptor (CD44) is expressed in bovine oocytes and early stage embryos. Theriogenology 60 1633-1644. (doi:10.1016/S0093691X(03)00116-X)

Gomes RCT, Verna C, Nader HB, Simoes RS, Dreyfuss JL, Martins JRM, Baracat EC, Simoes MJ \& Soares JM 2009 Concentration and distribution of hyaluronic acid in mouse uterus throughout the estrous cycle. Fertility and Sterility 92 785-792. (doi:10.1016/j.fertnstert.2008.07.005)

Itano N, Sawai T, Yoshida $M$, Lenas $P$, Yamada $Y$, Imagawa $M$, Shinomura $T$, Hamaguchi M, Yoshida Y, Ohnuki Y et al. 1999 Three isoforms of mammalian hyaluronan synthases have distinct enzymatic properties. Journal of Biological Chemistry 274 25085-25092. (doi:10.1074/jbc. 274.35.25085)

Jackson PGG 2004 Cesarean section. In Handbook of Veterinary Obstetrics, ch 11, pp 173-199. 2nd edn, Ed. PGG Jackson. Edinburgh, UK: Saunders.

Lee HG \& Cowman MK 1994 An agarose gel electrophoretic method for analysis of hyaluronan molecular weight distribution. Analytical Biochemistry 219 278-287. (doi:10.1006/abio.1994.1267)

Lee J \& Spicer A 2000 Hyaluronan: a multifunctional, megaDalton, stealth molecule. Current Opinion in Cell Biology 12 581-586. (doi:10.1016/ S0955-0674(00)00135-6)

Lepperdinger G, Mullegger J \& Kreil G 2001 Hyal2 - less active, but more versatile? Matrix Biology 20 509-514. (doi:10.1016/S0945-053X (01)00170-6) 
Matou-Nasri S, Gaffney J, Kumar S \& Slevin A 2009 Oligosaccharides of hyaluronan induce angiogenesis through distinct CD44 and RHAMM-mediated signalling pathways involving Cdc2 and $\gamma$-adducin. International Journal of Oncology 35 761-773. (doi:10.3892/ ijo_00000389)

McDonald JA \& Camenisch TD 2003 Hyaluronan: genetic insights into the complex biology of a simple polysaccharide. Glycoconjugate Journal 19 331-339. (doi:10.1023/A:1025369004783)

Nykopp TK, Rilla K, Sironen R, Tammi MI, Tammi RH, Hamalainen K, Heikkinen AM, Komulainen M, Kosma VM \& Anttila M 2009 Expression of hyaluronan synthases (HAS1-3) and hyaluronidases (HYAL1-2) in serous ovarian carcinomas: inverse correlation between HYAL1 and hyaluronan content. BMC Cancer 9 143. (doi:10.1186/14712407-9-143)

Nykopp TK, Rilla K, Tammi MI, Tammi RH, Sironen R, Hamalainen K, Kosma VM, Heinonen S \& Anttila M 2010 Hyaluronan synthases (HAS1-3) and hyaluronidases (HYAL1-2) in the accumulation of hyaluronan in endometrioid endometrial carcinoma. BMC Cancer 10 512. (doi:10.1186/1471-2407-10-512)

Paiva P, Vandamme M, Tellbach M, Jones R, Jobling T \& Salamonsen L 2005 Expression patterns of hyaluronan, hyaluronan synthases and hyaluronidases indicate a role for hyaluronan in the progression of endometrial cancer. Gynecologic Oncology 98 193-202. (doi:10.1016/j.ygyno. 2005.02.031)

Perry K, Haresign W, Wathes DC \& Khalid M 2010a Hyaluronan (HA) content, the ratio of HA fragments and the expression of CD44 in the ovine cervix vary with the stage of the oestrous cycle. Reproduction 140 133-141. (doi:10.1530/REP-09-0424)

Perry K, Haresign W, Wathes DC \& Khalid M 2010b Intracervical application of hyaluronan improves cervical relaxation in the ewe. Theriogenology 74 1685-1690. (doi:10.1016/j.theriogenology.2010. 07.008)

Pienimaki JP, Rilla K, Fulop C, Sironen R, Karvinen S, Pasonen S, Lammi MJ, Tammi R, Hascall VC \& Tammi MI 2001 Epidermal growth factor activates hyaluronan synthase 2 in epidermal keratinocytes and increases pericellular and intracellular hyaluronan. Journal of Biological Chemistry 276 20428-20435. (doi:10.1074/jbc.M007601200)

Pitsillides AA, Skerry TM \& Edwards CJ 1999 Joint immobilization reduces synovial fluid hyaluronan concentration and is accompanied by changes in the synovial intimal cell population. Rheumatology 38 1108-1112. (doi:10.1093/rheumatology/38.11.1108)

Ponglowhapan S, Church DB \& Khalid M 2008 Differences in the expression of luteinizing hormone and follicle stimulating hormone receptors in the lower urinary tract between intact and gonadectomised male and female dogs. Domestic Animal Endocrinology 34 339-351. (doi:10.1016/j.domaniend.2007.09.005)

Ponta H, Sherman L \& Herrlich PA 2003 CD44: from adhesion molecules to signalling regulators. Nature Reviews. Molecular Cell Biology 4 33-45. (doi:10.1038/nrm1004)

Recklies AD, White C, Melching L \& Roughley PJ 2001 Differential regulation and expression of hyaluronan synthases in human articular chondrocytes, synovial cells and osteosarcoma cells. Biochemical Journal 354 17-24. (doi:10.1042/0264-6021:3540017)

Roberts RM \& Bazer FW 1988 The functions of uterine secretions. Journal of Reproduction and Fertility 82 875-892. (doi:10.1530/jrf.0. 0820875)

Robinson RS, Pushpakumara PG, Cheng Z, Peters AR, Abayasekara DR \& Wathes DC 2002 Effects of dietary polyunsaturated fatty acids on ovarian and uterine function in lactating dairy cows. Reproduction 124 119-131. (doi:10.1530/rep.0.1240119)

Schoenfelder M \& Einspanier R 2003 Expression of hyaluronan synthases and corresponding hyaluronan receptors is differentially regulated during oocyte maturation in cattle. Biology of Reproduction 69 269-277. (doi:10.1095/biolreprod.102.011577)

Singh H, Nardo L, Kimber SJ \& Aplin JD 2010 Early stages of implantation as revealed by an in vitro model. Reproduction 139 905-914. (doi:10.1530/ REP-09-0271)
Slevin M, Krupinski J, Gaffney J, Matou S, West D, Delisser H, Savani RC \& Kumar S 2007 Hyaluronan-mediated angiogenesis in vascular disease: uncovering RHAMM and CD44 receptor signaling pathways. Matrix Biology 26 58-68. (doi:10.1016/j.matbio.2006.08.261)

Spencer TE \& Bazer FW 2002 Biology of Progesterone action during pregnancy recognition and maintenance of pregnancy. Frontiers in Bioscience 7 1879-1898. (doi:10.2741/spencer)

Spicer AP \& McDonald JA 1998 Characterization and molecular evolution of a vertebrate hyaluronan synthase gene family. Journal of Biological Chemistry 273 1923-1932. (doi:10.1074/jbc.273.4.1923)

Stern R 2003 Devising a pathway for hyaluronan catabolism: are we there yet? Glycobiology 13 105R-115R. (doi:10.1093/glycob/cwg112)

Stern R 2004 Hyaluronan catabolism: a new metabolic pathway. European Journal of Cell Biology 83 317-325. (doi:10.1078/0171-9335-00392)

Stern R, Asari A \& Sugahara K 2006 Hyaluronan fragments: an informationrich system. European Journal of Cell Biology 85 699-715. (doi:10.1016/ j.ejcb.2006.05.009)

Straach KJ, Shelton JM, Richardson JA, Hascall VC \& Mahendroo MS 2005 Regulation of hyaluronan expression during cervical ripening. Glycobiology 15 55-65. (doi:10.1093/glycob/cwh137)

Sunil N, Srinivasan N, Aruldhas MM \& Govindarajulu P 2000 Impact of oestradiol and progesterone on the glycosaminoglycans and their depolymerizing enzymes of the rat mammary gland. Acta Physiologica Scandinavica 168 385-392. (doi:10.1046/j.1365-201x.2000.00675.x)

Tammi MI, Day AJ \& Turley EA 2002 Hyaluronan and homeostasis: a balancing act. Journal of Biological Chemistry 277 4581-4584. (doi:10.1074/jbc.R100037200)

Tawil E, Simard R \& Methot Y 1973 The addition of progesterone to radiotherapy in cancer of the endometrium. Union Medicale du Canada 102 83-84.

Tellbach M, Salamonsen LA \& Van Damme M-P 2002 The influence of ovarian steroids on ovine endometrial glycosaminoglycans. Glycoconjugate Journal 19 385-394. (doi:10.1023/B:GLYC.0000004010.24877.2f)

Toole BP 2004 Hyaluronan: from extracellular glue to pericellular cue. Nature Reviews. Cancer 4 528-539. (doi:10.1038/nrc1391)

Uchiyama T, Sakuta T \& Kanayama T 2005 Regulation of hyaluronan synthases in mouse uterine cervix. Biochemical and Biophysical Research Communications 327 927-932. (doi:10.1016/j.bbrc.2004.12.092)

Wang Y, Hanifi-Moghaddam P, Hanekamp EE, Kloosterboer HJ, Franken P, Veldscholte J, van Doorn HC, Ewing PC, Kim JJ, Grootegoed JA et al. 2009 Progesterone inhibition of Wnt/ $\beta$-catenin signaling in normal endometrium and endometrial cancer. Clinical Cancer Research 15 5784-5793. (doi:10.1158/1078-0432.CCR-09-0814)

Wang YZ, Cao ML, Liu YW, He YQ, Yang CX \& Gao F 2011 CD44 mediates oligosaccharides of hyaluronan-induced proliferation, tube formation and signal transduction in endothelial cells. Experimental Biology and Medicine 236 84-90. (doi:10.1258/ebm.2010.010206)

Wathes DC, Mann GE, Payne JH, Riley PR, Stevenson KR \& Lamming GE 1996 Regulation of oxytocin, oestradiol and progesterone receptor concentrations in different uterine regions by oestradiol, progesterone and oxytocin in ovariectomized ewes. Journal of Endocrinology 151 375-393. (doi:10.1677/joe.0.1510375)

Wathes DC, Cheng Z, Fenwick MA, Fitzpatrick R \& Patton J 2011 Influence of energy balance on the somatotrophic axis and matrix metalloproteinase expression in the endometrium of the postpartum dairy cow. Reproduction 141 269-281. (doi:10.1530/REP-10-0177)

Weissmann B, Meyer K, Sampson P \& Linker A 1954 Isolation of oligosaccharides enzymatically produced from hyaluronic acid. Journal of Biological Chemistry 208 417-429.

Yoffou PH, Edjekouane L, Meunier L, Tremblay A, Provencher DM, Mes-Masson A-M \& Carmona E 2011 Subtype specific elevated expression of hyaluronidase-1 (HYAL-1) in epithelial ovarian cancer. PLOS ONE 6 e20705. (doi:10.1371/journal.pone.0020705)

Received 2 January 2013

First decision 25 January 2013

Accepted 11 March 2013 